Journal of Applied Pharmaceutical Science Vol. 5 (12), pp. 105-110, December, 2015

Available online at http://www.japsonline.com

DOI: $10.7324 / J A P S .2015 .501218$

ISSN 2231-3354 (cc)) BY-NC-SA

\title{
Green synthesis and characterization of Manganese nanoparticles using natural plant extracts and its evaluation of antimicrobial activity
}

\author{
M. Jayandran ${ }^{1}$, M. Muhamed Haneefa ${ }^{2 *}$, V. Balasubramanian ${ }^{2}$ \\ ${ }^{1}$ Department of Chemistry, Mahendra Engineering College, Namakkal-637503, India. \\ ${ }^{2}$ Department of Chemistry, AMET University, Chennai-603112, India.
}

\begin{tabular}{|c|c|}
\hline ARTICLE INFO & ABSTRACT \\
\hline Article history: & \multirow{9}{*}{$\begin{array}{l}\text { Green synthesis of metal nanoparticles is an interesting and expanding research area due to the potential } \\
\text { applications for the ecofriendly development of novel technologies. Generally, nanoparticles are prepared by a } \\
\text { variety of chemical and physical methods which are yield environmentally benign wastages largely. Present study } \\
\text { reported a simple, convenient and low cost method for the synthesis of manganese nanoparticles by reducing } \\
\text { manganese acetate with the help of easily available natural products viz., lemon extract as reducing agent and } \\
\text { turmeric curcumin as a stabilizing agent. The curcumin was isolated from turmeric by using solvent extraction } \\
\text { method and used for manganese nanoparticle stabilization. The characterization of curcumin and manganese } \\
\text { nanoparticles was done by using UV-Vis and FT-IR spectroscopic techniques. The morphology of manganese } \\
\text { nanoparticles was confirmed by SEM and TEM techniques. The size of MnNPs was in the ranges about } 50 \mathrm{~nm} \text {. } \\
\text { The antimicrobial activities of synthesized Mn nanoparticles were observed higher antimicrobial activity than the } \\
\text { standard drug against S. aureus, C. lunata and T. simii and also exhibited similar inhibition activity to standard } \\
\text { drug against E. coli, C. albicans, and A. niger. }\end{array}$} \\
\hline $3 / 09 / 2015$ & \\
\hline $\operatorname{Re}$ & \\
\hline $\mathrm{Ac}$ & \\
\hline Available online & \\
\hline Key words: & \\
\hline Curcumin, Extraction, Green & \\
\hline synthesis, Nanoparticles, & \\
\hline $\begin{array}{l}\text { Reducing and } \\
\text { agent. }\end{array}$ & \\
\hline
\end{tabular}

\section{INTRODUCTION}

Nanotechnology can be defined as the manipulation of atom by atom from the material world by the combination of engineering, chemical and biological approaches. Application of nano scale material and structures are usually ranging from 1-100 $\mathrm{nm}$ and is emerging area of nanoscience and nanotechnology (Catauro et al., 2004; Crabtree et al., 2003). Metal nanoparticles have a high specific surface area and a high fraction of surface atoms; have been studied extensively because of their unique physicochemical characteristics including catalytic, optical, electronic, magnetic properties and antimicrobial activities (Krolikowska et al., 2003; Zhao and Stevens, 1998). Most of the current strategies are usually working by the use of physical or chemical principles to synthesize metal nanoparticles. But both

\footnotetext{
* Corresponding Author

M. Muhamed Haneefa, Department of chemistry, AMET University, Chennai-603112, India. Email: honey79101@gmail.com.
}

preparation methods are not environmental friendly because of many drawbacks such as the presence of toxic organic solvents, production of hazardous by-products and intermediary compounds and high energy consumption (Jana et al., 2000; Bhattacharya and Rajinder, 2005). Nanotechnology is a revolutionary field just at its onset, the trend in the next decades being its integration with the green chemistry approach. Although nanoparticles can be synthesized through array of conventional methods green synthesis routes are good competent over the physical and chemical techniques. Green principle route of synthesizing have emerged as alternative to overcome the limitation of conventional methods (Salam et al., 2012; Sharma et al., 2009). Green synthesis mainly concerns the elimination of hazardous wastes and the utilization of sustainable processes, implementation of environmental friendly chemicals, solvents and renewable materials (Anastas and Warner, 1998; Matlack, 2001). In the green-nanotechnology, various metal nanoparticle synthesis have been reported using yeast, fungi, bacteria, algae, plant extract etc. 
From environmental point of view, plant extracts used reduction methods can be considered as more effective green approaches for synthesizing metal nanoparticles, because of employing plants towards synthesis of nanoparticles are emerging as advantageous compared to microbes with the presence of broad variability of bio-molecules in plants can act as capping and reducing agents (Duran et al., 2005; Duran et al., 2011; Narayanan, 2010). Thus increases the rate of reduction and stabilization of nanoparticles and synthesis can be performed under mild experimental conditions such as relatively low reaction temperature and ambient pressure (Carmona, 2010).

Manganese oxides can be applied in catalysts, molecularsieves, ion-sieves, batteries, magnetic materials as well as other applications such as water treatment, imaging contrast agents due to their excellent physicochemical properties (Reddy and Reddy, 2004; Chen et al., 2005). $\mathrm{MnO}_{2}$ is also one of the most important materials and a number of researchers pay attention to the influence of $\mathrm{MnO}_{2}$ addition on the electromagnetic properties of ferrite materials (Duan, 2007). Various approaches have been developed to prepare nanoscale $\mathrm{MnO}_{2}$ such as self-reacting micro emulsion (Kang et al., 2008), precipitation (Wei et al., 2008), room temperature solid reactions (Yuan et al., 2009), sonochemical (Zolfaghari et al., 2007) and hydrothermal methods (Yan et al., 2009). Although there are several reports of green synthesis of manganese nanoparticles in different manner, using plant extract reduction and stabilization of $\mathrm{Mn}$ metal into nanoparticle is the environment friendly, cheapest and simplest method in the view of green chemistry as discussed above (Satish et al., 2013; Begum et al., 2011; Philip et al., 2011). Curcumin is well known medicinal compound which has been shown to have a wide range of therapeutic effects but due to presence of olefinic groups in its structure this $\beta$-diketone of poor aqueous solubility rendering it of relatively low bioavailability. This can be remedied by the surface functionalization of Mn metal nanoparticles and the biological activities of synthesized nanoparticles are considerably increased (Aggarwal et al., 2007; Jain et al., 2011; Das et al., 2012). Most of the reports are focusing on the characterization and application of the formed manganese nanoparticles in catalytic activity, electronic properties, but the antimicrobial effects of manganese nanoparticles are investigated rarely.

Based upon the above discussions this investigation is dealing with the synthesis of Mn nanoparticles through green method by using lemon extract as a reductant and curcumin extracted from turmeric as a stabilizing agent. This work is mainly focusing the biological applications of Mn nanoparticles which mean antibacterial and antifungal activities against some bacterial and fungal strains.

\section{MATERIAL AND METHODS}

All the chemicals and solvents used were of analytical reagent grade and procured from Merck (India) Ltd and all samples were prepared by using fresh double-distilled water. Curcumin was isolated from turmeric (BSR-01) which was purchased from Agricultural College and Research Institute, Madurai, India.

\section{Collection of extracts}

Lemon fruits were collected from the local markets. They were washed in double distilled water, cut into pieces and squeezed well to make pure extract. The lemon extract was then filtered using Whatman's No. 1 filter paper. The filtrate was collected in a clean and dried container and it was stored for further uses.

Curcumin (CR) was extracted from turmeric by using soxhlet solvent extraction method in $95 \%$ ethanol medium. BSR01 turmeric variety was used in this method for better curcumin yield which was investigated in our previous research work (Haneefa et al., 2014). The final curcumin extract absorbance was measured at $425 \mathrm{~nm}$ against alcohol blank and the curcumin content was estimated as per Manjunath et al., 1991. The above ethanol residual extract was evaporated and dried then stored for further uses.

\section{Characterization}

The UV-Visible absorption spectra of the samples were measured on a Shimadzu UV-Vis V-530A spectrophotometer in the range of $425 \mathrm{~nm}$. The nanoparticles were examined for FT-IR spectra analysis and recorded on a Jasco FT-IR/4100 spectrophotometer with $4 \mathrm{~cm}^{-1}$ resolution in the range of 4000 to $400 \mathrm{~cm}^{-1}$. Scanning electron microscopy (SEM) images were recorded by using a JEOL Model JSM - 6390LV scanning electron microscope. High resolution transmission electron microscopy (HRTEM) was carried out using a $300 \mathrm{KV}$ JEOL-3011 instrument with an ultrahigh resolution pole piece to determine the morphological changes.

\section{Synthesis of manganese nanoparticles (MnNPs)}

An aqueous solution of Manganese acetate $(1 \mathrm{mM})$ was prepared for the synthesis of MnNPs. Double distilled water was used throughout the reaction. $\mathrm{pH}$ and temperature was maintained at particular extent to get better result. The manganese ions are reduced by the addition of freshly prepared manganese solution $(10 \mathrm{ml})$ with prepared stored pure lemon extract $(10 \mathrm{ml})$ in a beaker and the mixture was constantly stirred for the proper reduction of metal ions. The reaction mixture was kept in the magnetic hot stirrer at $50-60^{\circ} \mathrm{C}$ for an hour to occur color change from pale green to pale yellow which denoted the metal ion reduction. Then freshly prepared curcumin extract $(1 \mathrm{mM})$ was added with above solution mixture for stabilizing the nanoparticle and the stirring was continued for about an hour. The solution color was changed from yellow to yellowish brown slowly and finally a permanent reddish brown color was produced which indicated the complete stabilization of MnNPs. The main factors, $\mathrm{pH}$ was maintained between 3 and 4 and the temperature was at $50-60^{\circ} \mathrm{C}$ throughout the experiment. The solution was centrifuged with washing several times to obtain the pure MnNPs. The supernatant was decanted and kept in oven to dryness. 


\section{Biological assay}

The antibacterial activity of the synthesized MnNPs were tested by disc diffusion method against two gram-positive bacteria (Staphylococcus aureus and Bacillus subtilis), two gram negative bacteria (Escherichia coli and Staphylococcus bacillus) and antifungal activity was carried out by agar well diffusion method against four funguses (Candida albicans, Curvularia lunata, Aspergillus niger and Trichophyton simii). For disc diffusion method (Bauer et al., 1966), stock cultures incubated in nutrient agar were transferred to test tube of Muller-Hinton broth (MHB) for bacteria that were incubated for 24 hours at $37^{\circ} \mathrm{C}$. The cultures were diluted with fresh Muller-Hinton broth to get $2.0 \times 10^{6}$ CFU/ml for bacteria. The Muller Hinton Agar (MHA) plates were prepared by pouring $15 \mathrm{ml}$ of molten media into sterile petri plates. The sample was loaded placed on the surface of the cultured agar plates and incubated at $37^{\circ} \mathrm{C}$ for 24 hours then inhibition zones formed around the disc were measured and the results were compared with standard antibiotic, Chloramphenicol. For agar well diffusion method (Gomes et al., 2002), the fungal strains were suspended in sabouraud's dextrose broth for 6 hours to give concentration $10^{5} \mathrm{CFU} / \mathrm{ml}$ and then inoculated with the culture medium. A total of $8 \mathrm{~mm}$ diameter wells were punched into the agar and filled with the sample and solvent blanks (hydro alcohol and hexane). Standard antibiotic, Fluconazole (concentration 1 $\mathrm{mg} / \mathrm{ml}$ ) was used as positive control and fungal plates were incubated at $37^{\circ} \mathrm{C}$ for 72 hours. The diameters of zone of inhibition observed were measured.

\section{RESULTS AND DISCUSSION}

Synthesized MnNPs are known in the solution by the color changing from pale green to pale yellow due to metal ion reduction and from yellow to reddish brown color due to capping of stabilizing agent. The color change can be easily identified by the naked eye. It was clearly indicates that the formation of well reduced and stabilized MnNPs.

\section{UV-Vis spectra studies}

One of the most convenient techniques for characterization of nanoparticles is UV-Vis spectroscopy. The synthesized turmeric curcumin (CR) was confirmed by the strong broad absorption peak at around $425 \mathrm{~nm}$. This can be due either to an $n \rightarrow \pi^{*}$ transition or to a combination of $\pi \rightarrow \pi^{*}$ and $n \rightarrow \pi^{*}$ transitions which is shown in Figure 1. UV-vis spectroscopy of MnNPs (Fig. 2) showed maximum absorption at critical wavelength, corresponding to the absorption maxima of $\mathrm{Mn}$ nanoparticles that is $360 \mathrm{~nm}$. The appearance of absorption edge at $360 \mathrm{~nm}$ is a clear indication of the formation of Mn nanoparticles.

\section{FT-IR spectra studies}

Fourier transforms infrared (FT-IR) spectroscopy is known for its high sensitivity, especially in detecting inorganic and organic species with low content. The FT-IR spectrum of curcumin stabilized manganese nanoparticles is represented in Figure 3. The spectrum was recorded in the range of $4000-500 \mathrm{~cm}$ 1 . The FT-IR spectrum shows characteristic peaks. From the data obtained, the peak observed at $3650 \mathrm{~cm}^{-1}$ which can be assigned to the $-\mathrm{OH}$ stretching of water or ethanol present in the system. The weak broad band in the range of $2935 \mathrm{~cm}^{-1}$ which is assigned to $\mathrm{Ph}-\mathrm{OH}$ group of curcumin moiety. The $\mathrm{C}=\mathrm{O}$ stretching of curcumin at $1625 \mathrm{~cm}^{-1}$ was shifted to a higher wave number at $1704 \mathrm{~cm}^{-1}$ due to interaction with manganese nanoparticles. Three characteristic peaks in the range of $1574-1515 \mathrm{~cm}^{-1}$ confirms the aromatic unsaturation $(\mathrm{C}=\mathrm{C})$ of stabilized curcumin system. The absorption peak at $1393 \mathrm{~cm}^{-1}$ symbolized the bending band of adsorbed water of $\mathrm{Mn}$ nanoparticles. The $(\mathrm{C}-\mathrm{O})$ band presence which belongs to curcumin was assigned by the peaks found at $1026 \mathrm{~cm}^{-1}$ and $1160 \mathrm{~cm}^{-1}$. The two significant absorption peaks observed at $901 \mathrm{~cm}^{-1}$ and $730 \mathrm{~cm}^{-1}$ are corresponded to characteristic stretching bonds $\mathrm{O}-\mathrm{Mn}-\mathrm{O}$ which demonstrated the presence of the $\mathrm{MnO}_{2}$ nanoparticles in the sample.

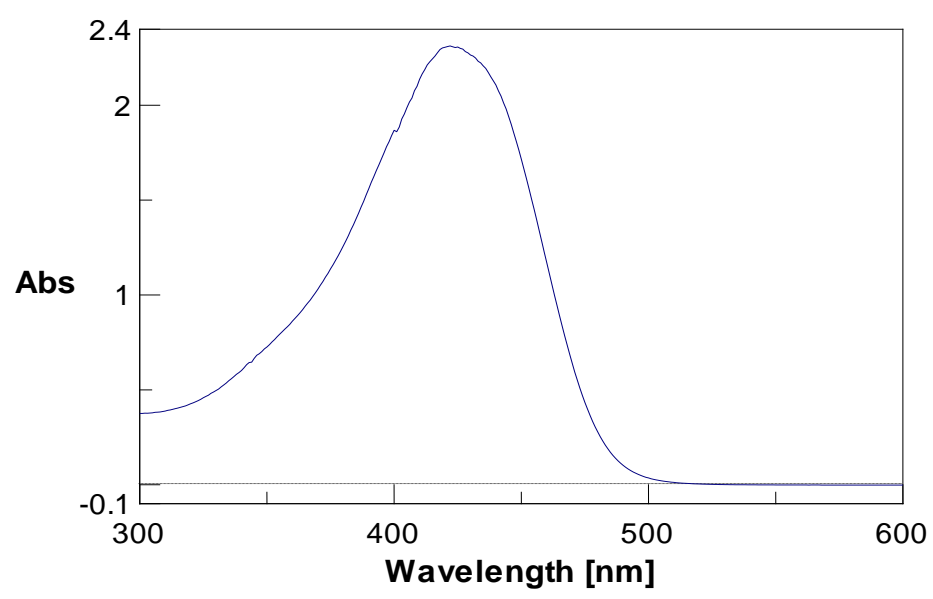

Fig. 1: UV-Vis spectra of curcumin.

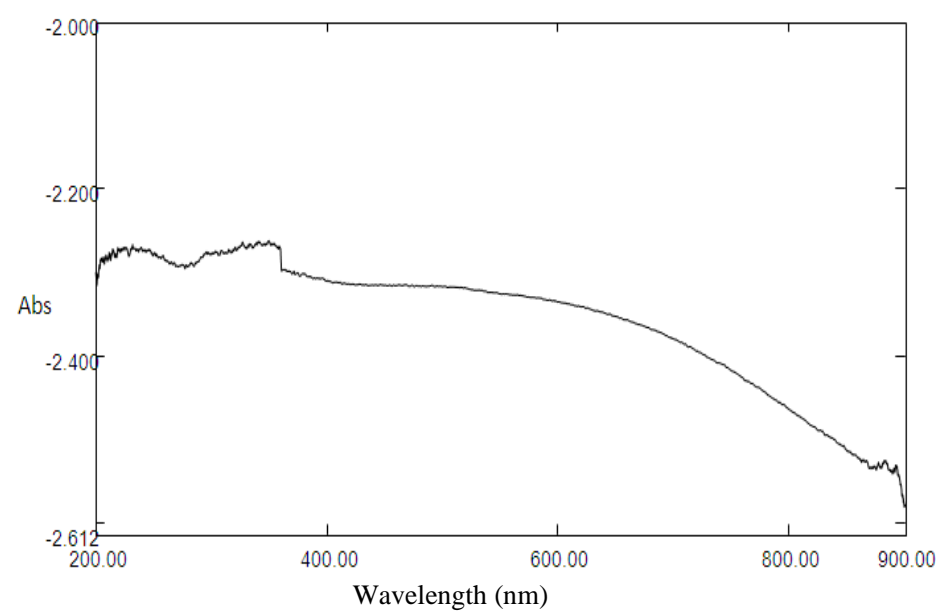

Fig. 2: UV-Vis spectra of Mn nanoparticles. 


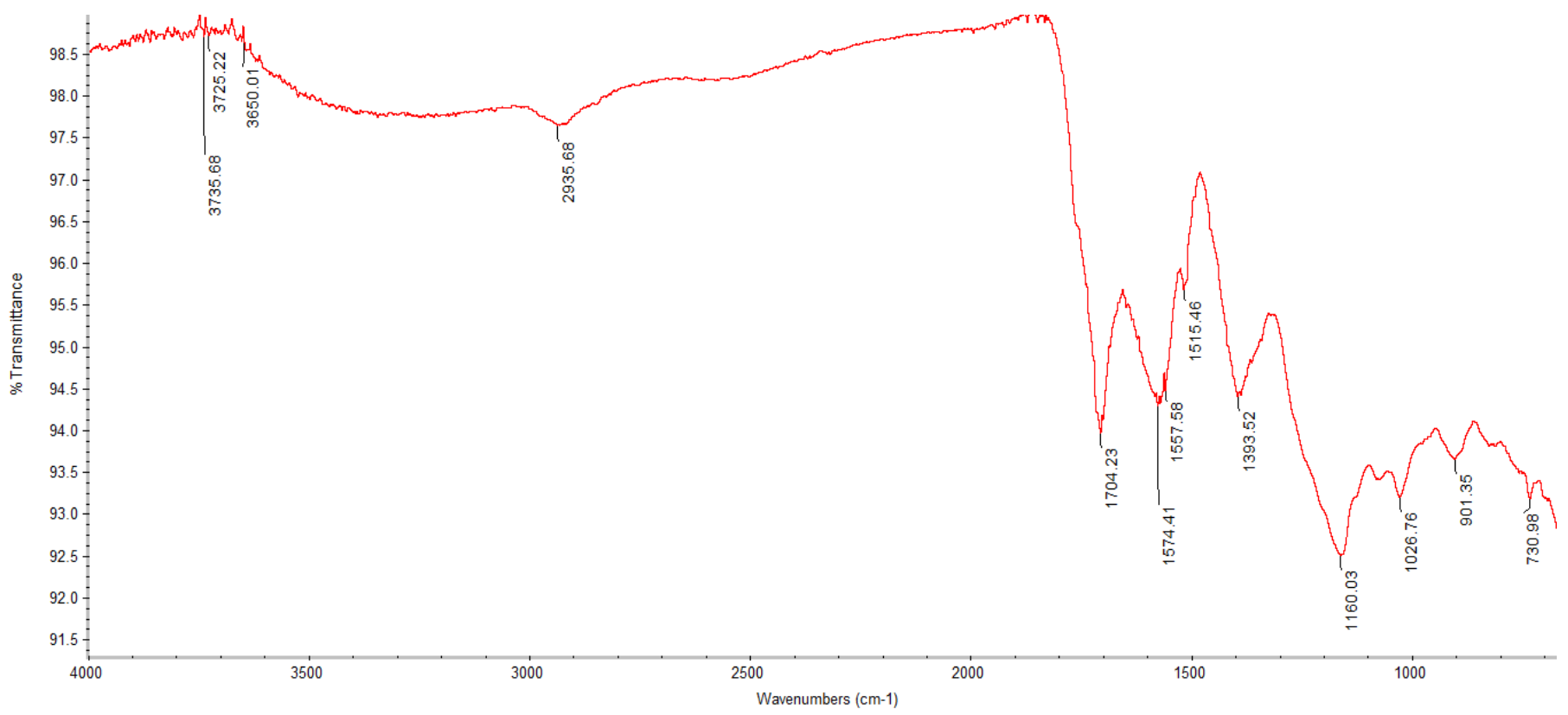

Fig. 3: FT-IR spectrum of Mn nanoparticles.

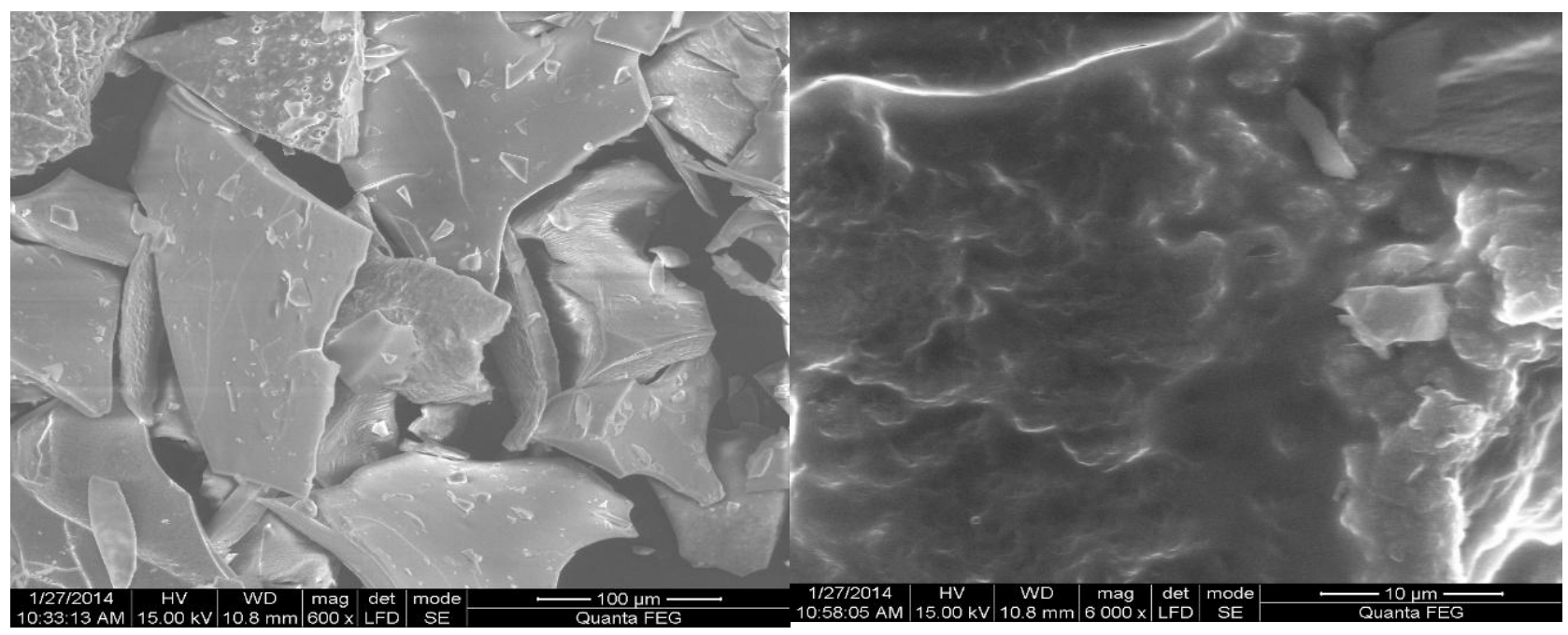

Fig. 4: SEM monographs of Mn nanoparticles.

\section{SEM studies}

Morphology of synthesized manganese nanoparticles was characterized by SEM analysis. The SEM images of manganese nanoparticles are shown in Figure 4 which exhibits the agglomeration occurred during the synthesis process.

It can be view that the MnNPs formed are moderately dispersed and slightly agglomerated. SEM images of those compounds had shown very clear that most of the particles are polymorphic morphology of material.

\section{TEM studies}

Figure 5 shows the TEM image of the manganese nanoparticles. Electron diffraction patterns were collected by HRTEM to identify the phase of nanoparticles and determine particle size.

These images shows that the particles formed are of nearly spherical and eclipse morphology. The nanoparticles are moderately dispersed and the average crystallite size of particles in the range of $50 \mathrm{~nm}$. 

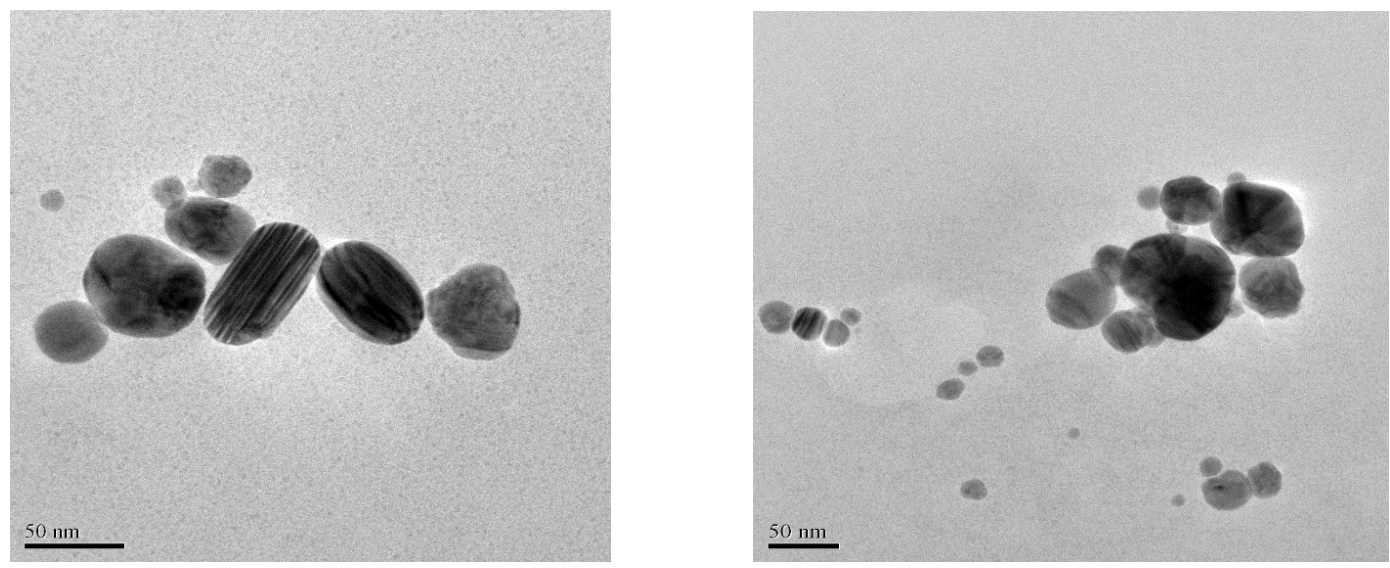

Fig. 5: TEM monographs of Mn nanoparticles.

\section{Antibacterial activity}

The antibacterial activity was performed on curcumin and curcumin stabilized manganese nanoparticles against two gram-positive (Staphylococcus aureus and Bacillus subtilis) and two gram-negative bacteria (Escherichia coli and Staphylococcus bacillus) were evaluated. The zone of inhibition was compared to a well-known commercial antibiotic Chloramphenicol.

Table 1: Effect of curcumin and manganese nanoparticles on antibacterial activity

\begin{tabular}{lccc}
\hline \multirow{2}{*}{ Bacterial Species } & \multicolumn{3}{c}{ Zone of inhibition diameter $\left(\mathbf{m m}\right.$ sample $\left.{ }^{-1}\right)$} \\
\cline { 2 - 4 } & $\begin{array}{c}\text { Standard } \\
\text { drug }(\mathbf{C})\end{array}$ & $\begin{array}{c}\text { Curcumin } \\
(\mathbf{C R})\end{array}$ & $\begin{array}{c}\text { Manganese } \\
\text { nanoparticles (MnNPs) }\end{array}$ \\
\hline S. aureus & 16 & 13 & 18 \\
B. subtilis & 18 & 16 & 11 \\
E. coli & 20 & 17 & 19 \\
S.bacillus & 21 & 15 & 17 \\
\hline
\end{tabular}

The results of the quantitative antibacterial assessment by disc diffusion are shown in table 1 and it was observed that the inhibition zone of curcumin stabilized manganese nanoparticles was higher than the raw curcumin for all bacterial strains over all. The MnNPs exhibited the strongest antibacterial activity against $S$. aureus and $E$. coli and it showed moderate activity against $S$. bacillus. Therefore the presence of an inhibition zone clearly indicates that the antibacterial activity of synthesized manganese nanoparticles against $S$. aureus is extremely superior to the standard drug, Chloramphenicol and nearly similar activity against E. coli bacteria. Hence we can say that the antibacterial activity showed by MnNPs from the test was significantly higher.

\section{Antifungal activity}

Curcumin and manganese nanoparticles were determined for their antifungal activity against four fungal strains Candida albicans, Curvularia lunata, Aspergillus niger and Trichophyton simii and their activity was compared with standard antifungal drug Fluconazole.

The results of the quantitative antifungal assessment by agar diffusion method are shown in table 2. There was observed clearly manganese nanoparticles exhibited excellent antifungal activity against all fungal strains when compared with raw curcumin. It indicates that well stabilization of curcumin with manganese nanoparticles, hence increased the biological activity of curcumin as well as antimicrobial activity nanoparticles. Surprisingly, the inhibition zones observed by MnNPs against $C$. lunata and $T$. simii were considerably higher than the standard drug Fluconazole. And also it has been showed similar activity of standard drug against $C$. albicans and nearly similar activity against $A$. niger. The antifungal activity of curcumin was moderately against all fungal strains.

Table 2: Effect of curcumin and manganese nanoparticles on antifungal activity

\begin{tabular}{cccc}
\hline \multirow{2}{*}{$\begin{array}{c}\text { Fungal } \\
\text { Species }\end{array}$} & $\begin{array}{c}\text { Zone of inhibition diameter }\left(\mathbf{m m} \text { sample }^{\mathbf{- 1}}\right) \\
\text { Standard } \\
\text { drug }(\mathbf{C})\end{array}$ & Curcumin $(\mathbf{C R})$ & $\begin{array}{c}\text { Manganese }_{\text {nanoparticles }} \\
\text { (MnNPs) }\end{array}$ \\
\hline C. albicans & 19 & 16 & 19 \\
C. lunata & 17 & 14 & 19 \\
A. niger & 20 & 15 & 18 \\
T. simii & 17 & 16 & 20 \\
\hline
\end{tabular}

\section{CONCLUSIONS}

In summary, manganese nanoparticles were synthesized by reducing the metal ions using natural lemon extract and selected turmeric plant (BSR-01) was used to synthesize bioactive curcumin and this curcumin extract was used as a stabilizer for manganese nanoparticles. This process was completely undertaken through green synthesis route. The synthesized Mn nanoparticles morphology and size were investigated by SEM and TEM analysis. The morphology study has been revealed the particle size was $50 \mathrm{~nm}$ and with spherical and eclipsed morphology. The antimicrobial activity was also investigated against two gram positive bacteria and two gram negative bacteria and four funguses. From the inhibition zone results, synthesized MnNPs were showed better inhibition activity than the standard drug against $S$. aureus, $C$. lunata and $T$. simii and also exhibited similar inhibition activity to standard drug against E. coli, C. albicans, A. niger. Thus our findings report Mn nanoparticles synthesized 
from the above proposed green method are show promise results in the view of pharmaceutical and therapeutic applications.

\section{ACKNOWLEDGEMENTS}

We thank AMET University, Chennai, India for their support to do this work. We gratefully acknowledge North-Eastern Hill University, Shillong, Meghalaya for TEM analysis and Nanotechnology Research Centre, SRM University, Chennai for SEM analysis facility. We also thank PG and Research Department of Chemistry, V. O. Chidambaram College, Tuticorin for providing IR spectral analysis facility and Department of Chemistry, SFR College for women, Sivakasi for providing UV analysis facility.

\section{REFERENCES}

Anand P, Kunnumakkara AP, Newman RA, Aggarwal BB. Bioavailability of Curcumin: Problems and Promises. Mol Pharmaceutics 2007; 4: 807-818.

Anastas PT, Warner JC. Green chemistry: Theory and practice. Oxford University Press, New York,1998: 30.

Almeida Gomes BP, Ferraz CC, Vianna ME. In vitro antimicrobial activity of calcium hydroxide pastes and their vehicles against selected microorganisms. Braz Dent J, 2002; 13: 155-161.

Bauer RW, Kirby MD, Sherris JC, Turck M. Antibiotic susceptibility testing by a standardized single disk method. American Journal of Clinical Pathology, 1966; 45: 493-496.

Bhawana, Basniwal RK, Buttar HS, Jain VK, Jain N. Curcumin nanoparticles: preparation, characterization and antimicrobial study $\mathrm{J}$ Agric Food Chem, 2011; 59: 2056-2061.

Bhattacharya D, Rajinder G. Nanotechnology and potential of microorganisms. Crit Rev Biotechnol, 2005; 25: 199-204.

Catauro M, Raucci MG, De Gaaetano FD, Marotta A. Antibacterial and bioactive silver-containing $\mathrm{Na}_{2} \mathrm{O} \cdot \mathrm{CaO} \cdot 2 \mathrm{SiO}_{2}$ glass prepared by sol-gel method.J Mater Sci Mater Med, 2004;15: 831-837.

Chen Y, Liu C, Li F, Cheng H. Preparation of single-crystal $\alpha$ $\mathrm{MnO}_{2}$ nanorods and nanoneedles from aqueous solution. J Alloys Compd, 2005; 397: 282-285.

Crabtree JH, Brruchette RJ, Siddiqi RA, Huen IT, Handott LL, Fishman A.The efficacy of silver-ion implanted catheters in reducing peritoneal dialysis-related infections. Perit Dial Int, 2003; 23: 368-374.

Duran N, Marcato PD, Alves OL, De souza GI, Esposito E. Mechanistic aspects of biosynthesis of silver nanoparticles by several Fusarium oxysporum strains. Journal of Nanobiotechnology, 2005; 3: 117.

Duran N, Marcato PD, Duran M, Yadav A, Gade A, Rai M. Mechanistic aspects in the biogenic synthesis of extracellular metal nanoparticles by peptides, bacteria, fungi and plants. Applied Microbiology and Biotechnology, 2011; 90: 1609-1624.

Ghosh D, Choudhury TS, Ghosh S, Mandal AK, Sakar S, Ghosh A, Saha KD, Das N. Nanocapsulated curcumin: oral chemopreventive formulationagainst diethylnitrosamine induced hepatocellular carcinoma in rat. Chemico-Biological Interactions, 2012; 195: 206-214.

Jana NR, Wang ZL, Sau TK, Pal T. Seed-mediated growth method to prepare cubic copper nanoparticles. Current Science, 2000; 79: 1367-1370.

Kavitha KS, Syed Baker, Rakshith D, Kavitha HU, Yashwantha Rao HC, Harini BP, Satish S. Plants as green source towards synthesis of nanoparticles. International Research Journal of Biological Sciences, 2013; 2: 66-76.

Krolikowska A, Kudelski A, Michota A, Bukowska J.SERS Studies on the structure of thioglycolic acid monolayers on silver and goldSurf Sci, 2003; 532: 227-232.
Manjunath MN, Sattigeri VD, Nagaraj KV. Curcumin in turmeric. Spice India, 1991; 12: 7-9.

Matlack AS. 2001. Introduction to green chemistry. 3rd ed., Marcel Decker Publishers, New York. pp. 3-7.

Mondal S, Roy N, Laskar RA, Sk I, Basu S, Mandal D, Begum NA. Biogenic synthesis of $\mathrm{Ag}, \mathrm{Au}$ and bimetallic $\mathrm{Au} / \mathrm{Ag}$ alloy nanoparticles using aqueous extract of mahogany (Swietenia mahogani JACQ) leaves. Colloids Surf B Biointerfaces, 2011; 82: 497-504.

Muhamed Haneefa M, Jayandran M, Anand B, Balasubramanian V, Muthumariappan S. Synthesis and characterization of bioactive curcumin derived from selected turmeric plants in India. International Journal of natural products research, 2014; 4: 82-87.

Narayanan KB, Sakthivel N. Biological synthesis of metal nanoparticles by microbes. Advanced in Colloid and Interface Science, 2010; 156: 1-13.

Reddy RN, Reddy RG. Synthesis and electrochemical characterization of amorphous $\mathrm{MnO}_{2}$ electrochemical capacitor electrode material. J Power Sources, 2004; 132: 315-320.

Rodriguez-carmona E, Villaverde A. Nanostructured bacterial materials for innovative medicines. Trends in Microbiology, 2010; 18: 423-430.

Salam HA, Rajiv P, Kamaraj M, Jagadeeswaran P, Gunalan S, Sivaraj R. Plants: Green route for nanoparticle synthesis. I Res J Biological Sci, 2012;1:85-90.

Sharma VK, Yagard RA, Lin Y. Silver nanoparticles: Green synthesis and their antimicrobial activities. Colloid and Interface Science, 2009; 145: 83-96.

Sheny DS, Mathew J, Philip D. Phytosynthesis of Au, Ag and $\mathrm{Au}-\mathrm{Ag}$ bimetallic nanoparticles using aqueous extract and dried leaf of Anacardium occidentale. Spectrochim Acta A Mol Biomol Spectrosc, 2011; 79: 254-262.

Subramanian V, Zhu H, Wei B. Alcohol-assisted room temperature synthesis of different nanostructured manganese oxides and their pseudocapacitance properties in neutral electrolyte. Chem Phys Lett, 2008; 453: 242-249.

Xu C, Li B, Du H, Kang F, Zeng Y.Electrochemical properties of nanosized hydrous manganese dioxide synthesized by a self-reacting microemulsion method. J Power Sources, 2008; 180: 664-670.

Yan D, Yan P, Cheng S, Chen JT, Zhuo RF, Feng JJ, Zhang GA.Fabrication, in-depth characterization, and formation mechanism of crystalline porous birnessite $\mathrm{MnO}_{2}$ film with amorphous bottom layers by hydrothermal method. Cryst Growth Des, 2009;9: 218-222.

Yuan A, Wang X, Wang Y, Hu J. Textural and capacitive characteristics of $\mathrm{MnO}_{2}$ nanocrystals derived from a novel solid-reaction route. Electrochim Acta, 2009; 54: 1021-1026.

Zhang X, Duan Y, Guan H, Liu S, Wen B. Effect of doping $\mathrm{MnO}_{2}$ on magnetic properties for M-type barium ferrite. J Magn Mater, 2007; 311: 507-511.

Zhao G, Stevens SE. Multiple parameters for the comprehensive evaluation of the susceptibility of Escherichia coli to the silver Ion. BioMetals, 1998; 11: 27-32.

Zolfaghari A, Ataherian F, Ghaemi M, Gholami A. Capacitive behavior of nanostructured $\mathrm{MnO}_{2}$ prepared by sonochemistry method. Electrochim Acta, 2007; 52: 2806-2814.

\section{How to cite this article:}

M. Jayandran, M. Muhamed haneefa, V. Balasubramanian. Green synthesis and characterization of Manganese nanoparticles using natural plant extracts and its evaluation of antimicrobial activity. $\mathrm{J}$ App Pharm Sci, 2015; 5 (12): 105-110. 